\title{
Coexisting schwannoma of the gallbladder and sarcoidosis: a case report
}

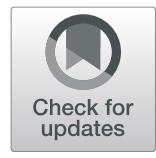

\author{
Takuya Tajiri, Hiromitsu Hayashi*, Takaaki Higashi, Takanobu Yamao, Toru Takematsu, Norio Uemura, \\ Kensuke Yamamura, Katsunori Imai, Yo-ichi Yamashita and Hideo Baba
}

\begin{abstract}
Background: Schwannomas originate from Schwann cells, which are constituents of peripheral nerve sheaths, and can occur anywhere in the body at any age. Most occur in soft tissues such as subcutaneous tissues and muscles, occurrence in the abdominal cavity being relatively rare. In particular, schwannomas of the gallbladder are extremely rare. We herein report a rare case of a schwannoma that coexisted with systemic sarcoidosis and presented as a steroid-resistant mass in the gallbladder wall.
\end{abstract}

Case presentation: A 40-year-old woman was found to have thickening of the gallbladder wall during a routine medical examination and was referred to our hospital, where she was found to have granular shadows in the lungs; mediastinal, cervical, intraperitoneal, and inguinal lymphadenopathy; parotid gland enlargement; and an erythematous skin rash. She was diagnosed as having systemic sarcoidosis by transbronchial lung biopsy and bronchoalveolar lavage. All her systemic mass lesions except for the one in the gallbladder resolved or became smaller with steroid treatment. The steroid-resistant gallbladder lesion showed enhancement on contrast-enhanced computed tomography and was shown by endoscopic ultrasonography to be a 30-mm-diameter gallbladder wall lesion. We performed laparoscopic cholecystectomy, which resulted in diagnosis of the steroid-resistant tumor as a schwannoma. Five months after surgery, the patient's prednisolone dosage had been gradually reduced to $5 \mathrm{mg} /$ day and she was doing well with no evidence of recurrence.

Conclusion: Resection of a steroid-resistant tumor resulted in diagnosis of schwannoma, enabling reduction in the patient's steroid dosage for sarcoidosis.

Keywords: Schwannoma, Gallbladder, Sarcoidosis, Steroid, Case report

\section{Background}

Schwannomas originate from Schwann cells, which are constituents of peripheral nerve sheaths, and can occur anywhere in the body at any age [1]. Most occur in soft tissues such as subcutaneous tissues and muscles, occurrence in the abdominal cavity being relatively rare. In particular, schwannomas of the gallbladder are extremely rare. We herein report a rare patient with a schwannoma of the gallbladder that coexisted with systemic sarcoidosis and presented as a steroid-resistant mass in the gallbladder wall.

\footnotetext{
* Correspondence: hhayasi@kumamoto-u.ac.jp

Department of Gastroenterological Surgery, Kumamoto University, 1-1-1 Honjo, Kumamoto 860-8556, Japan
}

\section{Springer Open}

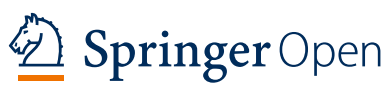

\section{Case presentation}

An asymptomatic 40-year-old woman was found to have gallbladder wall thickening during a routine medical examination. There was no medical history except for uveitis with recent blurred vision. She was taking no medications and had no history of allergy. Her vital signs were unremarkable. On physical examination, cervical and inguinal lymphadenopathy, parotid gland enlargement, and an erythematous skin rash were detected. Soluble interleukin-2 receptor and angiotensin-converting enzyme concentrations were $2431 \mathrm{U} / \mathrm{mL}$ (normal range 121-613) and 27.6 U/L (normal range 8.3-21.4), respectively. Other laboratory data, including tumor markers such as carcinoembryonic antigen (CEA) and carbohydrate antigen 199 (CA19-9), were within the normal range. Abdominal

(c) The Author(s). 2020 Open Access This article is licensed under a Creative Commons Attribution 4.0 International License, which permits use, sharing, adaptation, distribution and reproduction in any medium or format, as long as you give appropriate credit to the original author(s) and the source, provide a link to the Creative Commons licence, and indicate if changes were made. The images or other third party material in this article are included in the article's Creative Commons licence, unless indicated otherwise in a credit line to the material. If material is not included in the article's Creative Commons licence and your intended use is not permitted by statutory regulation or exceeds the permitted use, you will need to obtain permission directly from the copyright holder. To view a copy of this licence, visit http://creativecommons.org/licenses/by/4.0/. 
ultrasonography revealed a hypoechoic mass (30-mm diameter) with no posterior echo enhancement on the abdominal side of the body of the gallbladder (Fig. 1a). The hypoechoic mass had slightly irregular borders, was elliptical in shape, and was almost uniform in consistency. In addition, another hypoechoic mass (20-mm diameter) with a clear circular border was noted in the hepatoduodenal ligament and suspected of being an enlarged lymph node. Contrast-enhanced computed tomography (CECT) revealed a mass lesion of the gallbladder wall with a contrast effect (Fig. 1b). Also, bilateral parotid gland enlargement and enlargement of multiple lymph nodes around the right supraclavicular, mediastinum, lower thoracic para-esophageal, common hepatic artery, and hepatoduodenal ligament were detectable. These lymph nodes showed uptake on positron emission tomographycomputed tomography (PET-CT); however, the gallbladder lesion did not. This lesion revealed hypointensity on $\mathrm{T} 1$ and $\mathrm{T} 2$ images and no diffusion limitation on magnetic resonance imaging (MRI) (Fig. 1c). Transbronchial lung biopsy (TBLB) and bronchoalveolar lavage (BAL) were performed. Finally, our patient was diagnosed as having systemic sarcoidosis by biopsy. She was prescribed prednisolone (PSL) $25 \mathrm{mg} /$ day for the systemic sarcoidosis, resulting in complete resolution or reduction in size of all mass lesions except for the gallbladder lesion. Endoscopic ultrasonography (EUS) of the gallbladder lesion showed that the gallbladder lumen was intact and did not identify any mucosal lesions. It was concluded that she had a steroid-resistant lymph node in the gallbladder wall.
Excision of the gallbladder lesion by laparoscopic cholecystectomy was therefore performed (Fig. 2a). The patient was discharged on postoperative day 5 with no postoperative complications. The resected specimen measured $37 \times 17$ $\mathrm{mm}$, was yellowish-white in color, and contained an elastic hard mass under the gallbladder serosa (Fig. 2ba). Histopathological examination showed that the tumor was composed of spindle cells in an irregular palisade arrangement and Verocay body formation with no evidence of malignancy (Fig. 2c). The spindle cells were positive for S-100 protein on immunostaining. In addition, non-necrotic granulation, which is consistent with sarcoidosis, was found in part of the lamina propria (Fig. 2d). Finally, the gallbladder lesion was diagnosed as a schwannoma. Five months after surgery, the PSL dosage had been gradually reduced to $5 \mathrm{mg} /$ day and the patient was doing well with no evidence of recurrence.

\section{Discussion}

We here describe a patient with sarcoidosis and a coexisting schwannoma that presented as a steroid-resistant mass in the gallbladder wall. Intra-abdominal schwannomas have reportedly occurred in the intrahepatic duodenal ligament [2], pancreas [3], small mesentery [4], and colon [5]. To the best of our knowledge, only ten schwannomas in the gallbladder, including the present case, have been reported [6-9]. Schwannomas are histopathologically composed of spindle cells in a nuclear palisade arrangement and Verocay body formation [10]. On immunostaining, the spindle cells are characteristically

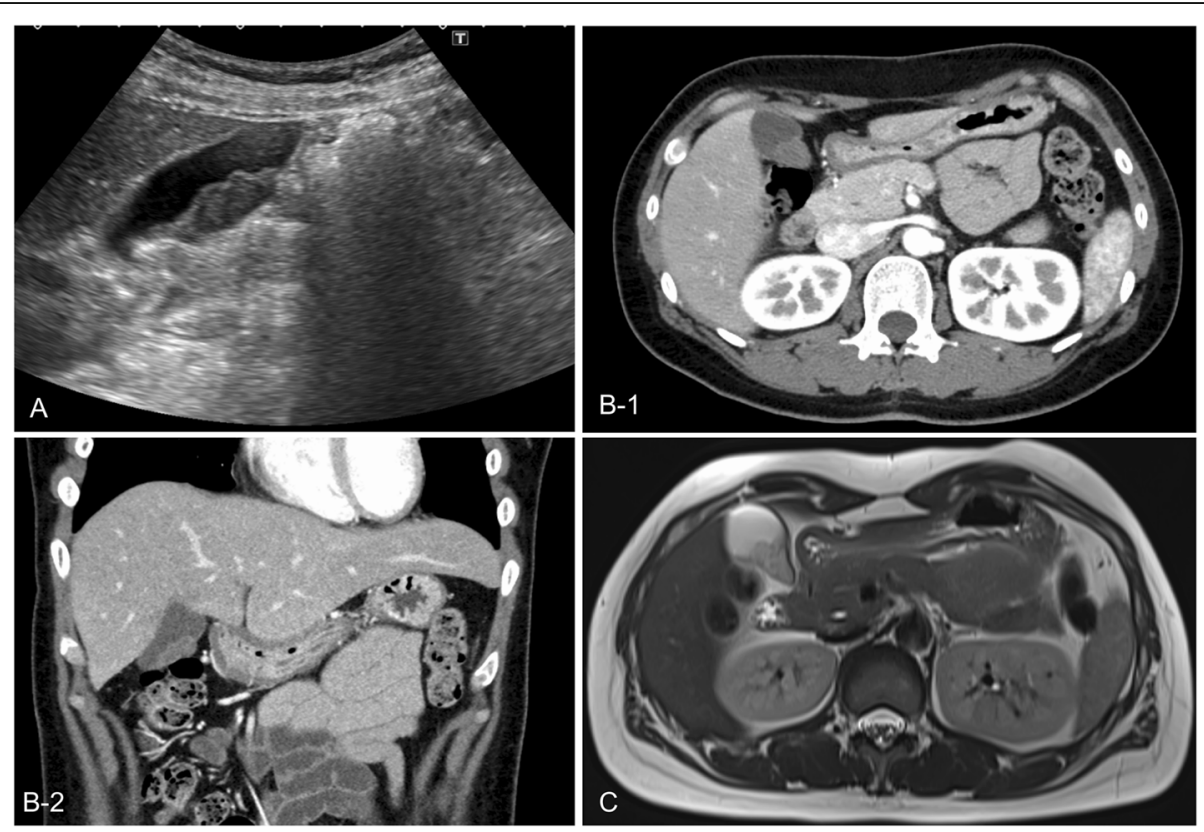

Fig. 1 a US image showing a mass in the gallbladder. b-1 CECT scan image showing a mass in the gallbladder wall that takes up contrast. b-2 CECT scan image showing a mass in the gallbladder wall that takes up contrast. c MRI T2 image showing a gallbladder lesion with hypointensity 


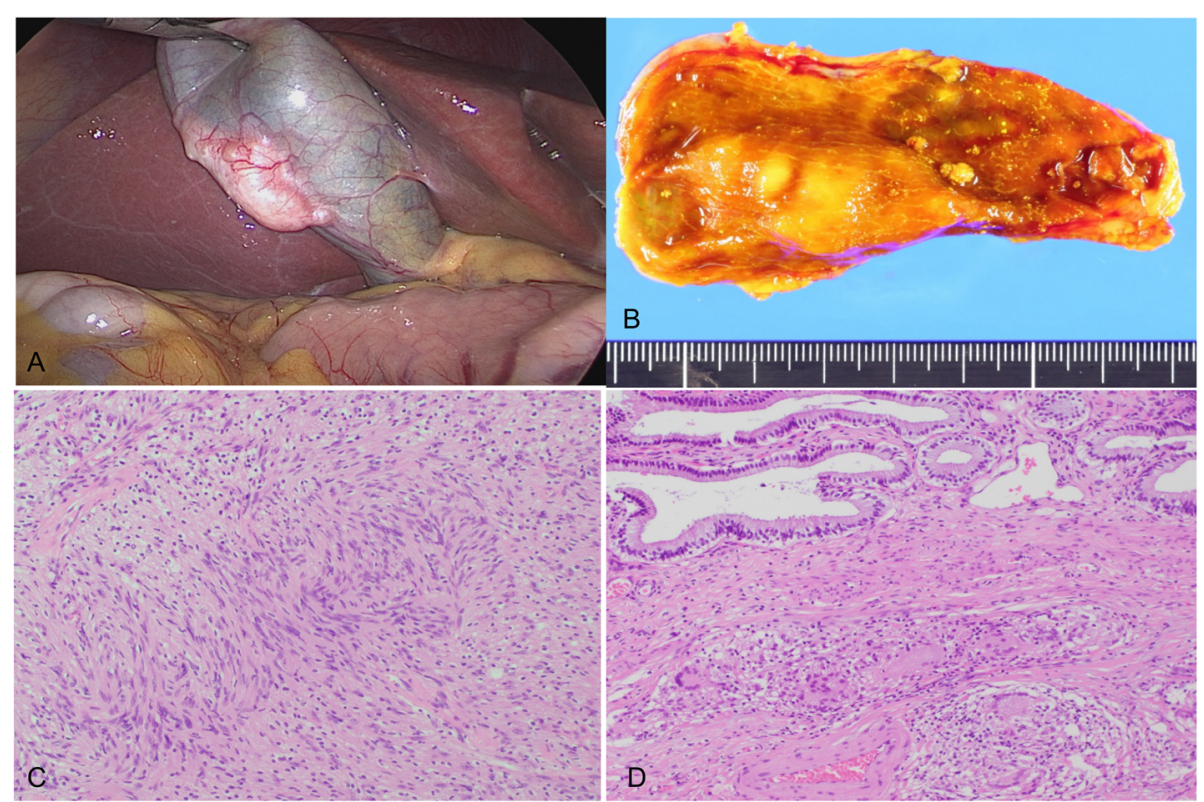

Fig. 2 a Photograph of gallbladder during laparoscopy. $\mathbf{b}$ Photograph of the resected specimen showing an elastic hard mass under the gallbladder serosa. $\mathbf{c}$ Photomicrograph of a section of the schwannoma (hematoxylin-eosin [HE] stain, $\times 100$ ). $\mathbf{d}$ Photomicrograph of HE-stained section of the tumor showing non-necrotic granulation consistent with sarcoidosis (× 100)

strongly positive for S-100 protein and negative for desmin, smooth muscle myosin, SMA, c-KIT, CD34, and CD117 [11]. As for clinical features, schwannomas that develop in the abdominal cavity are often asymptomatic for a long time, eventually presenting with symptoms of compression of surrounding organs [2].

Schwannomas arising in the digestive tract can be easily accessible to endoscopic biopsy, whereas it is difficult to obtain a biopsy of the gallbladder to make a definitive diagnosis [2]. Schwannomas have no distinctive imaging findings and the preoperative diagnosis is often difficult. Multiple imaging modalities such as contrast-enhanced US, CT, and MRI may be useful in making a diagnosis. Color Doppler ultrasound reportedly shows well-defined hypodense lesions with no echoic enhancement [12]. CECT shows welldefined hypodense lesions with encapsulation and/or cystic degeneration [11], and MRI shows hypointensity on T1weighted images and lack of homogeneity and hyperintensity on T2-weighted images [13, 14]. Contrast-enhanced US and CECT can evaluate the intra-tumor blood flow, enabling differentiation from malignant tumors [6].

In contrast, sarcoidosis is an inflammatory disease that is characterized by formation of granulomas (small nodules of immune cells) in the lungs, lymph nodes, and other organs. Sarcoidosis may be acute and resolve spontaneously, or be chronic and progressive [15]. More than $80 \%$ of cases occur in adults between 20 and 50 years of age [16]. Treatment is not indicated for patients with asymptomatic sarcoidosis because spontaneous resolution is common [16]. Treatment with corticosteroids should be considered for patients with significant symptomatic or progressive pulmonary disease or serious extrapulmonary disease [17]. An international consensus statement recommended prednisone (or its equivalent) at a starting dosage of 20 to $40 \mathrm{mg}$ per day for 4 to 6 weeks [16]. If the patient's condition is stable or improved, the dosage should be tapered slowly to approximately 5 to $10 \mathrm{mg}$ per day.

To the best of our knowledge, no relationship between sarcoidosis and schwannoma has been documented. The differential diagnosis for both sarcoidosis and schwannoma is broad because of the nonspecific symptoms and diverse clinical presentations. Because many other diseases present with similar clinical, radiologic, and pathologic findings, infections and malignancy (e.g., lymphoma) should be ruled out if suspected [17].

Our patient's schwannoma was complicated by her coexisting systemic sarcoidosis, which is an extremely rare combination. Because all lesions except for the one in the gallbladder were responsive to steroids, it was resected to obtain an accurate diagnosis, the rationale being that if it was not a sarcoid lesion, we could reduce her dosage of steroids.

In addition, in this case, the excised specimen showed a mixture of spindle-shaped lesions indicating a schwannoma and non-necrotic granulomatous lesions indicating sarcoidosis, which may have a component of neurosarcoidosis as reported by Bangiyev et al. [18].

\section{Conclusions}

Schwannomas in the abdominal cavity, including in the gallbladder, are rare. We excised our patient's steroid- 
resistant gallbladder mass to obtain a definitive diagnosis because she also had steroid-responsive systemic sarcoidosis. Excision provided an accurate diagnosis, resulting in more rational treatment.

\section{Abbreviations}

CECT: Contrast-enhanced computed tomography; PET-CT: Positron emission tomography-computed tomography; MRI: Magnetic resonance imaging; TBLB: Transbronchial lung biopsy; BAL: Bronchoalveolar lavage;

PSL: Prednisolone; EUS: Endoscopic ultrasonography; US: Ultrasonography

\section{Acknowledgements}

We thank Dr. Trish Reynolds, MBBS, FRACP, from Edanz Group (www. edanzediting.com/ac) for editing a draft of this manuscript.

\section{Presentation}

We have not presented this article anywhere.

\section{Authors' contributions}

TT described and designed the article. $\mathrm{HH}$ edited the article. HB supervised the editing of the manuscript. Other remaining co-authors collected the data and discussed the content of the manuscript. All authors read and approved the final manuscript.

\section{Authors' information}

Department of Gastroenterological Surgery, Graduate School of Life Sciences, Kumamoto University, 1-1-1 Honjo, Chuo-ku, Kumamoto, Kumamoto, 860 0811, Japan

\section{Funding}

This study was not funded.

\section{Availability of data and materials}

All data generated or analyzed during this study are included in this published article.

\section{Ethics approval and consent to participate}

Written informed consent was obtained from the patient for publication of this case report and any accompanying images.

\section{Consent for publication}

Written informed consent was obtained from the patient for publication of this case report and any accompanying images.

\section{Competing interests}

The authors declare that they have no conflict of interest.

Received: 14 March 2020 Accepted: 7 April 2020

Published online: 19 April 2020

\section{References}

1. Das Gupta TK, Brasfield RD, Strong EW, Hajdu SI. Benign solitary schwannomas (neurilemomas). Cancer. 1969;24(2):355-66.

2. Tokoro T, Makino I, Miyashita T, Tajima H, Takamura H, Ohta T. A case of schwannoma arisen in the hepatoduodenal ligament. J Japan Surg Assoc. 2018:79(4):885-92.

3. Ma Y, Shen B, Jia Y, Luo Y, Tian Y, Dong Z, et al. Pancreatic schwannoma: a case report and an updated 40-year review of the literature yielding 68 cases. BMC Cancer. 2017;17(1):853.

4. Tang S-X, Sun Y-H, Zhou X-R, Wang J. Bowel mesentery (meso-appendix) microcystic/reticular schwannoma: case report and literature review. World J Gastroenterol. 2014;20(5):1371-6.

5. Zippi M, Pica R, Scialpi R, Cassieri C, Avallone EV, Occhigrossi G. Schwannoma of the rectum: a case report and literature review. World J Clin Cases. 2013:1(1):49-51.

6. Liu LN, Xu HX, Zheng SG, Sun LP, Guo LH, Wu J. Solitary schwannoma of the gallbladder: a case report and literature review. World J Gastroenterol. 2014;20(21):6685-90
7. Evangelista $L$, Burei $M$, Basso U. A solitary metastasis for a malignant schwannoma in the gallbladder detected by 18F-FDG PET/CT. Clin Nucl Med. 2016;41(8):666-7.

8. Xu SY, Guo H, Shen Y, Sun K, Xie HY, Zhou L, et al. Multiple schwannomas synchronously occurring in the porta hepatis, liver, and gallbladder: first case report. Medicine (Baltimore). 2016;95(33):e4378.

9. Lin YX, Liu ZM, Fu YY, Jia QB. Unsuspected schwannomas of the gallbladder. Dig Liver Dis. 2018;50(3):310.

10. Joshi R. Learning from eponyms: Jose Verocay and Verocay bodies, Anton $A$ and B areas, Nils Antoni and Schwannomas. Indian Dermatol Online J. 2012;3(3):215-9.

11. Xu SY, Sun K, Xie HY, Zhou L, Zheng SS, Wang WL. Schwannoma in the hepatoduodenal ligament: a case report and literature review. World J Gastroenterol. 2016;22(46):10260-6.

12. Tao $L, X u S$, Ren $Z$, Lu Y, Kong $X$, Weng $X$, et al. Laparoscopic resection of benign schwannoma in the hepatoduodenal ligament: a case report and review of the literature. Oncol Lett. 2016:11(5):3349-53.

13. Devi J, Sathyalakshmi R, Chandramouleeswari K, Devi NR. Pancreatic schwannoma - a rare case report. J Clin Diagn Res. 2014;8(7):Fd15-6.

14. Rha SE, Byun JY, Jung SE, Chun HJ, Lee HG, Lee JM. Neurogenic tumors in the abdomen: tumor types and imaging characteristics. Radiographics. 2003 23(1):29-43.

15. Ahmadzai H, Huang S, Steinfort C, Markos J, Allen RK, Wakefield D, et al. Sarcoidosis: a state of the art review from the Thoracic Society of Australia and New Zealand. Med J Aust. 2018;208(11):499-504.

16. Statement on sarcoidosis. Joint Statement of the American Thoracic Society (ATS), the European Respiratory Society (ERS) and the World Association of Sarcoidosis and Other Granulomatous Disorders (WASOG) adopted by the ATS Board of Directors and by the ERS Executive Committee, February 1999. Am J Respir Crit Care Med. 1999;160(2):736-55. https://doi.org/10.1164/ ajrccm.160.2.ats4-99. PMID:10430755.

17. Soto-Gomez N, Peters Jl, Nambiar AM. Diagnosis and management of sarcoidosis. Am Fam Physician. 2016:93(10):840-8.

18. Bangiyev L, Kornacki S, Mikolaenko I. Rare isolated trigeminal nerve sarcoidosis mimicking schwannoma. Clin Imaging. 2015;39(1):133-5.

\section{Publisher's Note}

Springer Nature remains neutral with regard to jurisdictional claims in published maps and institutional affiliations.

\section{Submit your manuscript to a SpringerOpen ${ }^{\circ}$ journal and benefit from:}

- Convenient online submission

- Rigorous peer review

- Open access: articles freely available online

- High visibility within the field

- Retaining the copyright to your article

Submit your next manuscript at $\boldsymbol{\nabla}$ springeropen.com 